\title{
Histological Variants of Ovarian Tumour in Bangladeshi Women
}

\author{
Shafeya Khanam, ${ }^{1}$ Maliha Rashid, ${ }^{2}$ Zebunnessa Parvin, ${ }^{3}$ Shahnaz Akter Jahan,, Mirza Md. Asaduzzaman, ${ }^{5}$ \\ Samar Chandra Saha, ${ }^{6}$ Nahid Reaz ${ }^{7}$
}

\begin{abstract}
Objective: Types of ovarian tumour are widely divergent and no age group is immune from ovarian tumour; but certain ages are more vulnerable to develop certain types of tumours. By far, very few studies describing the histological types and subtypes of ovarian tumour in the context of Bangladeshi population have been conducted. The present study was intended to find the histological variants of ovarian tumours in our women.
\end{abstract}

Methods: The present study was carried out in Dhaka Medical College Hospital between July 2001 to June 2002. The total number of patients admitted with a clinical diagnosis of ovarian tumour during the study period was 238, while the total number of gynaecological admissions was 3189 . In the present study every alternate patients of ovarian tumour who consented to participate in the study were included as long as 110 cases were met. After admission, history and clinical presentation were recorded and every case was followed till discharge. Provisional diagnosis was made clinically and by ultrasound when 14 cases were excluded for they did not have ovarian tumour at all. The remaining 96 cases were operated and were confirmed by operative and histopathological findings.

Results: In the present study proportion of ovarian tumours was $6.52 \%$ of all gynecological admissions. The mean age of the patients was found to be $39.5 \pm 6.3$ years. The peak age incidence of benign ovarian tumors was found to lie between 21-50 years. Malignant ovarian tumors, however was found more commonly after the age of 50 years. After histopathological confirmation of the precise nature of the 96 ovarian tumors, it was found that benign tumour comprised $77 \%$ of the cases with malignant tumors occurring in the rest $23 \%$. Among them tumours of epithelial origin formed $70.8 \%$ of all ovarian tumors, germ cell tumors $25 \%$ and sex-cord stromal tumours made up $4.2 \%$. Among the epithelial tumors, serous tumors were most frequently seen $(61.7 \%)$, followed by mucinous tumors $(35.3 \%)$. The percentage of benign serous cystadenomas was $35.5 \%$. The ratio between serous and mucinous cystadenocarcinoma was almost 2:1. Germ cell tumour found in this study was of moderate frequency (25\%). Among them $15.6 \%$ were mature teratoma (dermoid cyst) followed by $5.2 \%$ dysgerminoma. Endodermal sinus tumors were relatively low $(3.1 \%)$ and there was a case of immature or malignant teratoma. Sex-cord-stromal tumours were of lowest frequency (4.2\%) and classified as ovarian fibroma, granulosa-cell tumor and Krukenberg tumour.

Conclusion: The study concluded that benign tumour comprised three-quarters of all ovarian tumours with the rest being malignant. Tumours of epithelial origin forms the main bulk, germ cell tumors about one-quarter and sex-cord stromal and metastatic tumors the least. Among the epithelial tumors, serous tumors were most frequently seen, followed by mucinous tumors.

Key words: Ovarian tumours, variants of ovarian tumours, Bangladeshi women.

\section{Authors' information:}

' Dr. Shafeya Khanam, MBBS, BCS (Health), FCPS, MS, Assistant Professor (Obstetrics \& Gynaecology), Faridpur Medical College \& Hospital, Faridpur.

2 Dr. Maliha Rashid, MBBS (Dhaka), FCPS (Obstetrics \& Gynaecology), Professor \& Academic coordinator, Central Hospital Ltd., Dhaka, 1207.

${ }^{3}$ Dr. Zebunnessa Parvin, Associate Professor, MCPS, DGO, FCPS, (Obstetrics \& Gynaecology), Faridpur Medical College \& Hospital, Faridpur.

${ }^{4}$ Dr. Shahnaz Akter Jahan, Assistant Registrar, MS (Obstetrics \& Gynaecology), Central Police Hospital, Rajarbag, Dhaka, 1000.

${ }^{5}$ Dr. Mirza Md. Asaduzzaman, Junior Consultant, Gynae Oncology Department, National Institute of Cancer Research and Hospital (NICRH), Mohakhali, Dhaka.

${ }^{6}$ Dr. Samar Chandra Saha, Registrar, Department of Anesthesiology \& ICU, Holy Family Red Crescent Medical College Hospital, Dhaka.

${ }^{7}$ Dr. Nahid Reaz, Assistant Registrar, MS (Obstetrics \& Gynaecology), Central Police Hospital, Rajarbag, Dhaka, 1000.

Correspondence: Dr. Shafeya Khanam, Cell Phone: +88 01711-158720, E-mail: shafeyakhanam@gmail.com 


\section{INTRODUCTION}

Ovarian tumours occur at all ages but certain ages are more vulnerable to certain type of tumours. Dermoid can occur at any ages, but $90 \%$ occur in women of reproductive age, so that they are the commonest ovarian cysts to be found in pregnancy. Germ cell tumours are found mostly in the $3^{\text {rd }}$ and $4^{\text {th }}$ decades of life. Ovarian neoplasms found in childhood are usually malignant or locally malignant. Otherwise the risk of malignancy is roughly proportional to age ranges (20\% before menopause and $50-60 \%$ afterwards). ${ }^{1}$ The influence of hormones on the incidence of ovarian cancer has been studied. ${ }^{2}$ They pointed out that ovarian cancer is less common in women of high parity and that pregnancy would seem to be protective whether ending in an abortion or at term. La Vecchia et $a^{2}$ have shown that an early age of first pregnancy confers a greater protection against ovarian cancer than does high parity. Breast-feeding can also be protective. An early menarche and a late menopause are associated with an increased risk. Newhouse et $\mathrm{al}^{3}$ first described the protective effect of oral contraception and they believe that the longer the pill is used, the less the likelihood of subsequent ovarian cancer.

Ovarian tumours become an abdominal structure when it enlarges and displaces the intestines above and to the side. The uterus usually lies below and behind its lower pole. On abdominal examination an ovarian tumour is therefore always dull on percussion with areas of resonance in the flanks. ${ }^{1}$ This simple and obvious sign allows a clear distinction between an ovarian cyst and ascites in nearly all cases.

Types of ovarian tumour are widely divergent and all age groups are at risk of developing the condition; but certain ages are more vulnerable to develop certain types of tumours. By far, very few studies describing the histological types and subtypes of ovarian tumour in the context of Bangladeshi population have been conducted. The present study is, therefore, intended to find the histological variants of ovarian tumours in our women.

\section{MATERIALS AND METHODS}

The present study was carried out in Dhaka Medical College Hospital over a period of one year between
July 2001 to June 2002. The total number of patients admitted for ovarian tumour during the study period was 238 , while the total number of gynaecological admissions was 3189 . The required sample size was determined to be 98. In the present study every alternate patients of ovarian tumour who consented to participate in the study were included as long as 110 cases were met. After admission history and clinical presentation were recorded and every case was followed till discharge. Provisional diagnosis was made clinically and by ultrasound when 14 cases were excluded for they did not have ovarian tumour at all. The remaining 96 cases were operated and were confirmed by operative findings and histopathological report. Statistical analysis was done using descriptive statistics like frequency with corresponding percentage and mean, standard deviation and range.

\section{RESULTS}

Age distribution of the patients shows that nearly two-thirds $(65.7 \%)$ of the patients were in their $2^{\text {nd }}$ and $4^{\text {th }}$ decades of life with mean age being 39.5 years. Majority of the patients was married $(89.6 \%)$ and multiparous (86.1\%). Over one-third (36.7\%) was poor, $57.3 \%$ were middle class and only $6.2 \%$ rich. Five patients had family history of ovarian tumour; of them 1 had family history of malignant ovarian tumour (Table I). Majority $(84.4 \%)$ of the patients was in the reproductive years of life. Some $12.5 \%$ were postmenopausal and a few were premenstrual (3.1\%). Most menstruating women had regular cycle $(88.9 \%)$ with average menstrual flow (92.6\%). More than half $(54.2 \%)$ of the patients never used any contraceptive methods, $31.2 \%$ used oral contraceptive and the rest $(14.6 \%)$ had experience of using barrier method $(6.3 \%)$, injectable method $(4.2 \%)$, IUCD (3.1\%) etc.(Table II).

The predominant complaint was abdominal lump (84.4\%) followed by vague abdominal discomfort $(65.6 \%)$, abdominal distension $(45.8 \%)$, loss of weight $(28.1 \%)$, increased urinary frequency $(23.9 \%)$, sudden severe abdominal pain with nausea, vomiting and pyrexia (18.7\%) and so on. Abdominal lump was the predominant sign 
(84.4\%). Anaemia was present in more than $90 \%$ cases with mild, moderate and severe anaemia being $35.4,41.7 \& 13.5 \%$ respectively. Tenderness over the lump and ascites was observed in 26 and $16.7 \%$ cases respectively (Table III).

\begin{tabular}{|c|c|c|}
\hline Demographic characteristics & requency & Percentage \\
\hline \multicolumn{3}{|l|}{ Age (years) } \\
\hline$\leq 20$ & 12 & 12.5 \\
\hline $21-50$ & 63 & 65.7 \\
\hline$>50$ & 21 & 21.8 \\
\hline \multicolumn{3}{|l|}{ Marital status } \\
\hline Unmarried & 10 & 10.4 \\
\hline Married & 86 & 89.6 \\
\hline \multicolumn{3}{|l|}{ Parity } \\
\hline Nulliparous & 12 & 13.9 \\
\hline Multiparous & 74 & 86.1 \\
\hline \multicolumn{3}{|l|}{ Socioeconomic status } \\
\hline Poor & 35 & 36.5 \\
\hline Middle & 55 & 57.3 \\
\hline Rich & 6 & 6.2 \\
\hline \multicolumn{3}{|l|}{ Family history } \\
\hline No family history & 91 & 94.8 \\
\hline Family history of benign ovarian tumour & 4 & 4.1 \\
\hline Family history of malignant ovarian tumour & ur 1 & 1.1 \\
\hline
\end{tabular}

TABLE II. Distribution of patients by their menstrual pattern \& contraceptive behaviour

\begin{tabular}{lcc|} 
Menstrual pattern \& complications & Frequency & Percentage \\
Menstrual status $(\mathbf{n}=96)$ & & \\
$\quad$ Premenstrual & 3 & 3.1 \\
$\quad$ Reproductive age (menstruating) & 81 & 84.4 \\
$\quad$ Postmenopausal & 12 & 12.5 \\
Menstrual cycle ( $\mathbf{n}=81)$ & & \\
$\quad$ Regular cycle & 72 & 88.9 \\
$\quad$ Irregular cycle & 9 & 11.1 \\
Menstrual flow $(\mathbf{n}=81)$ & & \\
$\quad$ Average flow & 75 & 92.6 \\
Heavy flow & 1 & 1.2 \\
$\quad$ Scanty flow & 5 & 6.2 \\
Use of contraceptives $(\mathbf{n}=96)$ & & \\
$\quad$ Never used any method & 52 & 54.2 \\
Oral pill & 30 & 31.2 \\
Injectable & 4 & 4.2 \\
IUCD & 3 & 3.1 \\
Barrier method & 6 & 6.3 \\
Sterilization & 1 & 1.0
\end{tabular}

$80 \%$ patients had unilateral ovarian tumour and $77 \%$ of the tumours were cystic in consistency. Metastatic deposit was found in $14.5 \%$ cases (Table IV).

\begin{tabular}{|c|c|c|}
\hline Clinical presentation & Erequency & Percentage \\
\hline \multicolumn{3}{|l|}{ Symptoms of patients } \\
\hline Abdominal lump & 81 & 84.4 \\
\hline Vague abdominal discomfort & 63 & 65.6 \\
\hline Abdominal fullness/distension & 44 & 45.8 \\
\hline Loss of body weight & 27 & 28.1 \\
\hline Increased urinary frequency & 23 & 23.9 \\
\hline Features of dyspepsia (loss of appetite/flatulenc & nce) 19 & 19.8 \\
\hline $\begin{array}{l}\text { Sudden severe abdominal pain with } \\
\text { nausea, vomiting, pyrexia }\end{array}$ & 18 & 18.7 \\
\hline Urinary retention & 8 & 8.3 \\
\hline Difficulty in defecation & 3 & 3.1 \\
\hline Abnormal vaginal bleeding & 10 & 10.4 \\
\hline Respiratory distress & 11 & 11.5 \\
\hline \multicolumn{3}{|l|}{ Physical signs } \\
\hline Abdominal lump & 81 & 84.4 \\
\hline \multicolumn{3}{|l|}{ Anaemia } \\
\hline Absent & 9 & 9.4 \\
\hline Mild & 34 & 35.4 \\
\hline Moderate & 40 & 41.7 \\
\hline Severe & 13 & 13.5 \\
\hline Tenderness & 25 & 26.0 \\
\hline Ascites & 16 & 16.7 \\
\hline
\end{tabular}

TABLE IV. Distribution of patients by their USG findings $(n=96)$

$\begin{array}{lcc}\text { USG findings } & \text { Frequency } & \text { Percentage } \\ \begin{array}{l}\text { Involvement } \\ \text { Unilateral }\end{array} & 77 & 80.2 \\ \quad \text { Bilateral } & 19 & 19.8 \\ \text { Consistency } & & \\ \text { Solid } & 8 & 8.3 \\ \text { Cystic } & 74 & 77.2 \\ \text { Partly solid, partly cystic/complex } & 14 & 14.5 \\ \text { Ascites } & 19 & 19.7 \\ \text { Metastatic deposits } & 14 & 14.5\end{array}$

Laparotomy findings confirmed that $79.2 \%$ of the tumours were unilateral $(43.7 \%$ right-sided and $35.4 \%$ left-sided). Nearly $80 \%$ of the tumours were free from adhesion to the surrounding structures and the rest exhibited adhesion to gut, omentum, bladder or exhibited extensive adhesion to whole abdominal structures. Peritoneal fluid was absent in 
$79.2 \%$ cases. Clear fluid was present in 14.6 and haemorrhagic in $6.2 \%$ cases.

\begin{tabular}{|c|c|c|}
\hline Laparotomy findings & Frequency & Percentage \\
\hline \multicolumn{3}{|l|}{ Involvement } \\
\hline Bilateral & 20 & 20.8 \\
\hline Right sided & 42 & 43.7 \\
\hline Left sided & 34 & 35.4 \\
\hline \multicolumn{3}{|c|}{ Adhesion to surrounding structures } \\
\hline No adhesions & 76 & 79.2 \\
\hline Omentum & 14 & 14.5 \\
\hline Gut & 02 & 2.1 \\
\hline Extensive to whole abdomen & 04 & 4.2 \\
\hline \multicolumn{3}{|l|}{ Peritoneal fluid/Ascites } \\
\hline Absent & 76 & 79.2 \\
\hline Clear fluid & 14 & 14.6 \\
\hline Haemorrhagic fluid & 06 & 6.2 \\
\hline \multicolumn{3}{|c|}{ Intraperitoneal metastatic deposits } \\
\hline Present & 09 & 9.4 \\
\hline Absent & 87 & 90.6 \\
\hline
\end{tabular}

TABLE VI. Distribution of patients by their histopathological variety $(n=96)$

$\begin{array}{lcc}\text { Histopathological variety } & \text { Frequency } & \text { Percentage } \\ \text { Surface epithelial tumours } & \mathbf{6 8} & \mathbf{7 0 . 8} \\ \text { Serous cystadenoma } & 34 & 35.5 \\ \text { Mucinous cystadenoma } & 21 & 21.8 \\ \text { Serous papillary cystadenocarcinoma } & 07 & 7.3 \\ \text { Mucinous cystadenocarcinoma } & 03 & 3.1 \\ \text { Serous papillary cystadenoma (borderline) } & 01 & 1.1 \\ \text { Clear cell (mesonephroid) carcinoma } & 01 & 1.1 \\ \text { Poorly differentiated adenocarcinoma } & 01 & 1.1 \\ \text { Germ cell tumours } & \mathbf{2 4} & \mathbf{2 5 . 0} \\ \text { Dermoid cyst } & 15 & 15.6 \\ \text { Dysgerminoma } & 05 & 5.2 \\ \text { Endodermal sinus tumour } & 03 & 3.1 \\ \text { Immature malignant teratoma } & 01 & 1.1 \\ \text { Sex cord-stromal tumours } & 04 & 4.2 \\ \text { Ovarian fibroma } & 02 & 2.1 \\ \text { Granulosa cell tumour } & 01 & 1.1 \\ \text { Secondary (Krukenberg) tumours } & 01 & 1.1\end{array}$

Intraperitoneal metastatic deposite was evident in 9.4\% cases (Table V). Histopathological examination shows surface epithelial tumours to form the main bulk (70.8\%) followed by germ-cell tumour (25\%) and sex-cord tumours (4.2\%). The subtypes of these three varieties are illustrated in Table VI. Among the subtypes serous cystadenoma, mucinous cystademona were predominant in surface epithelial tumours and dermoid cyst in germ cell tumous.

\section{DISCUSSION}

Most tumours of ovary can be placed into one of three categories-surface epithelial, stromal tumours, sex cord-stromal tumours and germ cell tumours according to the anatomic structures from which the tumours presumably originate. Each category includes a number of subtypes. Combinations of different subtypes within a single tumour are found with some frequency. Tumours that combine two or more subtypes are designated as mixed, with contributing subtypes specified in the designation. By convention, for classification purposes, tumour subtypes making up $<10 \%$ of the total tumour mass are ignored. ${ }^{4}$ Quite often, non-neoplastic ovarian enlargement is initially labeled as ovarian tumour. Follicular cyst is the commonest of all non-neoplastic enlargement of ovary. In the present study proportion of ovarian tumours was $6.52 \%$ of all gynecological admissions. Ovarian tumors may occur in all ages. In the present study the mean age of the patients was found to be 39.5 years which is quite consistent with Malkasian et $\mathrm{al}^{5}$ who in a similar study of 612 cases found a mean age of 42.6 years. According to Novak et $\mathrm{al}^{6}$ the peak age incidence of ovarian tumor lies between 31 to 40 years with mean age of onset being 36 years which also compares well with the findings of the present study, where as peak age incidence of benign ovarian tumors was found between 21 to 50 years. Malignant ovarian tumors, however was found more commonly after the age of 50 years. Hormone producing tumors are seen at the extremes of life.

It is quite well-known that high parity is considered to be a protective factor against the growth of ovarian tumor. ${ }^{7}$ Pregnancies irrespective of whether continued till term or aborted offer substantial protection. To address this point a control group of patients is needed. No tenable argument can be made with a descriptive study 
like this one which included only cases. Ovarian tumours usually do not affect menstruation (unless they are hormone producing) as was evident with menstrual profile of the present study cases ( $89 \%$ of women had regular menstrual cycle with $92.6 \%$ having average menstrual flow). The reason is that even for a large ovarian tumour and even when both ovaries are involved, there remains some healthy compressed ovarian tissue to secrete hormones to maintain menstruation regularly. Nevertheless 30 percent of postmenopausal women suffering from ovarian tumour experience abnormal uterine bleeding. ${ }^{1}$

According to some authority surface epithelial tumors comprise $70-80 \%$, germ cell tumors $15 \%$, sex cord-stromal tumors $10 \%$ and tumors of metastatic origin $5 \%$ of all ovarian tumors. ${ }^{1}$ Serous and mucinous cystadenocarcinoma are the most common varieties of invasive epithelial ovarian cancers encountered, constituting about $90 \%$ of the malignant tumors of ovary. ${ }^{4}$ The ratio of serous to mucinous cystadenocarcinoma varies between $4: 1$ and 10:1 in different parts of the world. ${ }^{1}$ The incidence of serous tumors as a whole is quoted to be around $30 \%$ of all ovarian tumours, with mucinous tumor accounting for $20 \%$ and mature teratomas for $10-15 \% .^{1}$ In this study, after histopathological confirmation of the precise nature of the 96 ovarian tumors, it was found that benign tumour comprised $77 \%$ of the cases with malignant tumors occurring in the rest $23 \%$. Among them tumours of epithelial origin constituted $70.8 \%$ of all ovarian tumors, germ cell tumors $25 \%$ and sex-cord stromal tumours made up $4.2 \%$ each.

Among the epithelial tumors serous tumors were most frequently seen $(61.7 \%$ ) (42 out of 68 epithelial tumors), followed by mucinous tumors (35.3\%) (24 out of 68 of epithelial tumors). Only a single case of each of clear cell (mesonephroid) tumor and poorly differentiated carcinoma was seen. The proportion of benign serous cystadenomas $(35.5 \%)$ was quite similar to that of a previous study $(40 \%) .{ }^{8}$ The ratio between serous and mucinous cystadenocarcinoma was almost $2: 1$, which is close to that found in a recent study $(2: 1){ }^{8}$

Germ cell tumour found in the present study was of moderate frequency (25\%). Among them $15.6 \%$ were mature teratoma (dermoid cyst) followed by $5.2 \%$ dysgerminoma. Endodermal sinus tumors were found with relatively low frequency $(3.1 \%)$ and there was a case of immature or malignant teratoma. Sex-cord-stromal tumours were of lowest frequency $(4.2 \%)$ which was classified as ovarian fibroma $(2.1 \%)$, granulosa-cell tumor $(1.1 \%)$ and Krukenberg tumour (1.1\%). A somewhat higher prevalence was found for Krukenberg's tumor $(4 \%)$ in a previous study. ${ }^{8}$

\section{CONCLUSION}

The study concluded that benign tumour comprised three-quarters of all ovarian tumours with the rest being malignat. Tumours of epithelial origin constituted more than seventy percent, germ cell tumors $26 \%$ and sex-cord stromal and metastatic tumors the least. Among the epithelial tumors, serous tumors were most frequently seen, followed by mucinous tumors.

\section{REFERENCES}

1. Bhatia N. Jeffcoate's Principles of Gynaecology. $6^{\text {th }}$ edition, London: Arnold publishers. 2001:503-40.

2. Vecchia $C L$, Franceschi $S$, Gallus G, Decarli A, Liberati A, Tognoni G. Incessant ovulation and ovarian cancer: a critical approach. Int J Epidemiol 1983;12(2):161-4

3. Newhouse ML, Pearson RM, Fullerton JM, Boesen EA, Shannon HS. A case control study of carcinoma of the ovary. Br J Prev Soc Med 1977;31(3):148-53.

4. Chen VW, Ruiz B, Killeen JL, Coté TR, Wu XC, Correa CN. Pathology and classification of ovarian tumors. Cancer 2003;97(10): S2631-S2642. doi:10.1002/cncr.11345.

5. Malkasian GD jr, Dockerty MB. Symmonds RE. Benign cystic teratomas. Obstet Gynecol 1967;29:719-25.

6. Novak E, Woodruff D, Novak ER. Probable mesonephric origin of certain female genital tumors. Am Obstet Gynecol 1954;68(5):1222-42.

7. Beral V, Fraser P, Chilvers C. Does pregnancy protect against ovarian cancer? Lancet 1978;1(8073):1083-87.

8. Chowdhury SA. Clinical presentation and histological pattern of overian tumour [dissertation] Bangladesh college of physician Surgeons, 1998. 